\title{
An Experimental and Computational Study of the Fluid Dynamics of Dense Cooling Air-Mists
}

\author{
Jesús I. Minchaca M., A. Humberto Castillejos E. ${ }^{*}$ and F. Andrés Acosta G. \\ Centre for Research and Advanced Studies - CINVESTAV, Unidad Saltillo \\ Mexico
}

\section{Introduction}

Spray cooling of a hot body takes place when a dispersion of fine droplets impinges upon its surface to remove a large amount of heat by evaporation and convection (Deb \& Yao, 1989). In metallurgical processes such as continuous casting of steel (Camporredondo et al., 2004) the surface temperature, $T_{w}$, of the hot steel strand exceeds considerably the saturation temperature, $T_{s}$, of the cooling liquid (water), i.e., $T_{w}-T_{s}$ ranges between $\sim 600$ to $1100^{\circ} \mathrm{C}$. These harsh temperature conditions have traditionally called for the use of high water impact fluxes $\left(\mathrm{w}, \mathrm{L} / \mathrm{m}^{2} \mathrm{~s}\right)$ to remove the heat arriving to the surface as a result of the solidification of the liquid or semi-liquid core of the strand. The boundary between dilute and dense sprays has been specified at $\mathrm{w}=2 \mathrm{~L} / \mathrm{m}^{2} \mathrm{~s}$ (Deb \& Yao, 1989, Sozbir et al., 2003). In modern continuous casting machines the $\mathrm{w}$ found are well above this value. Most of the impingement area of the spray or mist jets will have $w>10 \mathrm{~L} / \mathrm{m}^{2} \mathrm{~s}$, with regions where $\mathrm{w}$ can be as large as $\sim 110 \mathrm{~L} / \mathrm{m}^{2} \mathrm{~s}$. Heat treatment of alloys requiring the rapid removal of large amounts of heat also makes use of dense sprays or mists (Totten \& Bates, 1993).

Sprays and air-mists are dispersions of drops produced by single-fluid (e.g., water) and twin-fluid (e.g. water-air) nozzles, respectively. In sprays, the energy to fragment the water into drops is provided by the pressure drop generated across the narrow exit orifice, while in air-mists nozzles a high speed air-stream breaks the water-stream generating fine, fastmoving droplets (Lefebvre, 1989; Nasr et al., 2002). In air-mist nozzles with internal mixing and perpendicular inlets for the fluids, as those shown in Fig. 1, the water splatters against a deflector surface and the resulting splashes are further split by the shear forces exerted by the axial air-stream, which also accelerates the drops as they move along the mixing chamber toward the exit port. Thus, the liquid emerges in the form of drops with different sizes and velocities and with a non-uniform spatial distribution (Hernández et al., 2008).

In addition to $\mathrm{w}$, the size, $\mathrm{d}_{\mathrm{d}}$, and velocity, $\mathrm{u}$, of the drops in dense air-mists play a crucial role in the cooling of highly superheated surfaces (Bendig et al., 1995; Jenkins et al., 1991; Hernández et al., 2011). This behavior stresses the important relationship between the heat transfer process and the droplet impact or deformation and break-up behavior. Since, for a specified fluid those two parameters, $d_{d}$ and $u$, determine the local impingement Weber number $\left(W e_{z s}=\rho_{d} u_{z s}{ }^{2} d_{d} / \sigma\right)$, which in general has been agreed to characterize the impact behavior (Wachters \& Westerling, 1966; Araki \& Moriyama, 1981; Issa \& Yao, 2005). As the

${ }^{*}$ Corresponding Author 
impingement Weber number increases the drops tend to deform more widely, break more profusely, stay closer to the surface and agitate more intensively the liquid film formed by previous drops. Thus, it is clear that knowledge of the local parameters characterizing free mist-jets is needed to arrive to a quantitative description of the fluid dynamic interaction of drops with a surface and of the boiling-convection heat transfer that would result.

Experimentally, the water impact flux has been the parameter most frequently determined, using a patternator (Camporredondo et al., 2004; Puschmann \& Specht, 2004). The drop size distribution in mists has often been measured by: (a) laser diffraction (Jenkins et al., 1991; Bul, 2001), (b) phase Doppler particle analysis, PDPA (Bendig et al., 1995; Puschmann \& Specht, 2004) and (c) particle/droplet image analysis, PDIA (Minchaca et al., 2011). The last two methods allow the simultaneous determination of the droplet velocity and hence of the correlation between both parameters. To the best knowledge of the authors only PDIA has been used for the characterization of dense sprays and mists. Particle image velocimetry, PIV, has been employed for measuring the velocity of drops in dense mists, but the technique did not allow the simultaneous determination of size (Hernández et al., 2008). Recent works have presented a detailed experimental characterization of the local variation of $\mathrm{w}, \mathrm{d}_{\mathrm{d}}$ and $\mathrm{u}$ obtained with typical air-mist nozzles, operating over a wide range of conditions of practical interest (Minchaca et al., 2011; Hernández et al., 2011).

The phenomena involved in the atomization of a liquid stream are very complex and therefore the generation of drops and their motion are generally treated separately. Knowledge of the influence of the fluid physical properties, nozzle design and operating conditions on atomization is crucial to generate drops with the size distribution that would perform better the task for which they are intended. The best well-known method for modeling drop size distributions is the empirical method (Babinski \& Sojka, 2002). This consists in fitting a curve to data collected over a wide range of nozzles and operating conditions. In the case of nozzles with internal mixing and $90^{\circ}$ intersecting streams of air and water, the number and volume frequency distributions of drop size have been adequately modeled by log-normal and Nukiyama-Tanasawa, NT, distribution functions (Minchaca et al., 2011), respectively. The statistical parameters of the distributions have been correlated with the water and air inlet pressures allowing the prediction of different characteristic mean diameters, over a wide range of operating conditions. Alternative modeling approaches are the maximum entropy and the discrete probability function methods (Babinski \& Sojka, 2002).

Two-phase flow models generally treat the continuous phase (e.g., air) in an Eulerian frame of reference while the disperse phase (e.g., water droplets) is considered by either one of two approaches: (a) Eulerian representation, which treats it as a continuum whose characteristics (e.g., velocity, concentration, etc) are declared and updated at grid cells shared with the continuous phase, and (b) Lagrangian representation, where the drops characteristics (e.g., position, velocity, concentration, etc) are tracked along their path-lines (Crowe et al., 1998). The Eulerian-Eulerian approach is best suited for flows of monodisperse or narrow size range drops. But models have been developed to handle efficiently polydisperse sprays by describing the distribution of sizes through the moments of the droplet distribution function (Beck \& Watkins, 2002). The Eulerian-Lagrangian approach can handle more efficiently a large range of particle sizes and give more details of the behavior of individual particles and of their interaction with walls. Both approaches use submodels to represent phenomena such as droplet break-up, droplet-droplet collisions, droplets-wall interaction, etc.

A two-dimensional (2-D) transient Eulerian-Lagrangian model was developed to describe the motion of air and drops in a domain that included the nozzle chamber, the free jet and 
the impingement region (Hatta et al., 1991a, 1991b). The researchers considered monodisperse drops with sizes of 1 and $10 \mu \mathrm{m}$ and found that the motion of both phases depended strongly on the particle size. More recently, a computational model was developed to calculate the in-flight and impingement motion of air and droplets with a size distribution (Issa \& Yao, 2005). The rebounding of multiple drops from the surface was simulated by extending empirical information regarding the variation of the normal coefficient of restitution of single droplets with the impingement $\mathrm{We}_{\mathrm{zs}}$. The authors claimed that large drops with high momentum tended to impinge closer to the stagnation point, whereas smaller drops tended to collision farther away because they were entrained by the air. In another study, the equation of motion for drops projected horizontally in quiescent air was solved considering sizes ranging from 100 to $1000 \mu \mathrm{m}$ and velocities of $20 \mathrm{~m} / \mathrm{s}$ and $50 \mathrm{~m} / \mathrm{s}$ (Ciofalo et al., 2007). It was found that drops smaller than $100 \mu \mathrm{m}$ would experience large deflections due to gravity, and would never reach a plane beyond $0.25 \mathrm{~m}$.

The sprays and mists that have been studied experimentally and computationally are far apart from those used in important metallurgical processes. In recent studies the authors presented a 3-D computational fluid dynamic (CFD) Eulerian-Lagrangian model for free dense air-mist jets (Hernández et al., 2008). However, since new and rigorous experimental information has been generated the model has been refined in regard to the size distribution imposed at the nozzle orifice. The experimental information generated in this work has also enabled to carry out a detailed validation of the model. The model predicts very well the correlation between drop velocity and particle size, the velocity and trajectory of the drops and the water impact density as a function of the nozzle operating conditions, over the whole range of practical interest.

\section{Experimental methods and conditions}

A schematic of the experimental set-up used for measuring the mist parameters is displayed in Figure 1. It consists of: (a) a patternator for measuring water impact density distribution, (b) a particle/droplet image analysis, PDIA, system for acquiring and analyzing the images of fine moving droplets to determine their size and velocity and (c) a water and air supply system for the nozzle.

To determine $\mathrm{w}$ the nozzle was oriented horizontally and this parameter was evaluated collecting the drops entering tubes with an area a, to measure the total volume of water $\mathrm{v}$ accumulated during a period of time $t$ in the bottles connected to the tubes. The collecting tubes were arranged forming a grid and their diameter and spacing are given in Figure 1. Hence, the local water impact flux at a position $x-y-z$ was calculated according to the following expression,

$$
w(x, y, z)=\frac{v(x, y, z)}{(a \cos \gamma) t}
$$

where $(\cos \gamma)$ is the direction cosine of the angle formed between the nozzle axis and the line connecting the centers of the nozzle orifice and of a given tube, i.e., (a $\cos \gamma$ ) gives the projected area of a tube perpendicular to the direction of motion of the drops. The accuracy of the measured $\mathrm{w}$ distributions was verified by integrating $\mathrm{w}$ over the impingement area to compare it with the total water flow rate, $W$. In general, the computed $W$ had an error smaller than $\pm 10 \%$. 

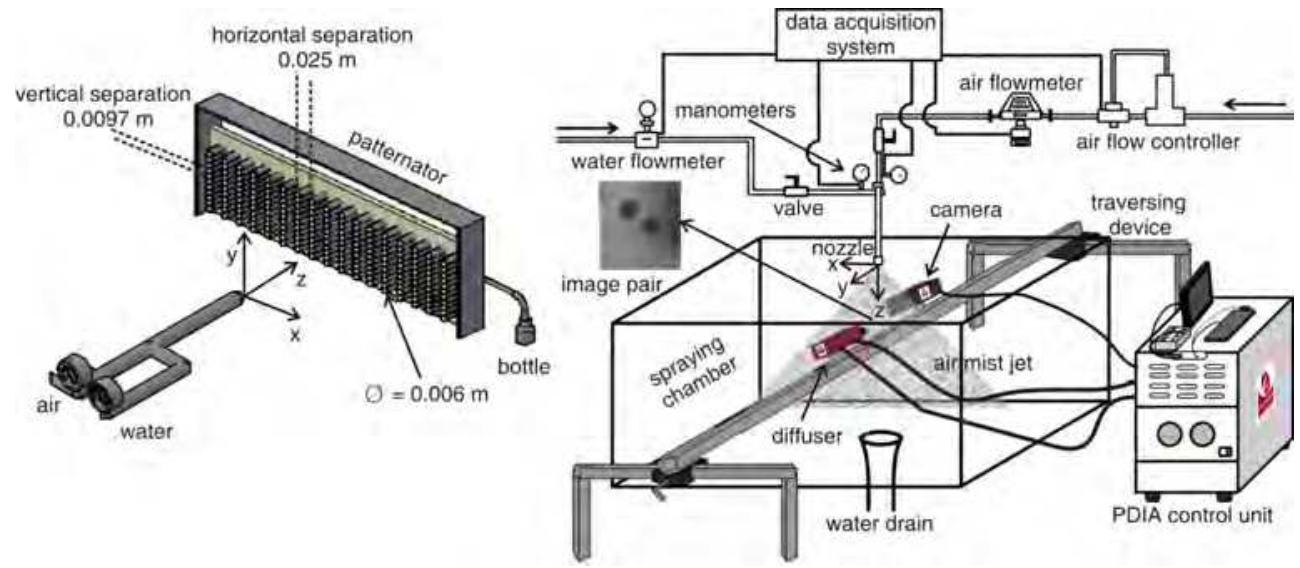

Fig. 1. Schematic of experimental setup

The PDIA system (VisiSizer N60V, Oxford Laser Ltd. Didcot, United Kingdom) schematically illustrated in Fig. 1 is a spatial multiple counting apparatus that captures instantaneously (i.e., in $4 \mathrm{~ns})$ shadow images of the droplets moving through a thin $(\sim 400 \mu \mathrm{m})$ sampling volume and analyzes them in real time (Minchaca et al., 2011). A dual head Nd:YAG laser sends light pulses $(15 \mathrm{~mJ}$ at $532 \mathrm{~nm})$ through a fluorescent diffuser to illuminate the region of interest from behind while a high resolution camera placed in front captures the shadow images of the objects passing in between. The disposition of these elements is illustrated in the figure. Operating in dual pulse mode the laser and camera are triggered to capture image pairs separated by a time interval of $1.7 \mu \mathrm{s}$, the figure displays a single pair extracted from superposed frames. The analysis of single and superposed frames allows, respectively, the simultaneous determination of the size and velocity of the drops appearing. The criteria employed for the consideration of single drops and drop pairs have been described elsewhere and were validated by off-line analysis of single and superposed frames (Minchaca, 2011; Minchaca et al., 2011). Lenses with two magnifications $(2 \times, 4 \times)$ were employed to resolve the whole spectrum of drop sizes. With each magnification 1000 frames were captured to obtain samples with over 5500 drops that ensured statistical confidence limits of $95 \%$ (Bowen \& Davies, 1951). The magnifications allowed resolving drops with sizes ranging from $5 \mu \mathrm{m}$ to 366 $\mu \mathrm{m}$ and velocities of up to $185 \mathrm{~m} / \mathrm{s}$. The field of view with both magnifications was $2.561 \times 2.561 \mathrm{~mm}^{2}$, which allowed combination of the samples obtained from both to carry out statistical analysis of the data. The calibration (i.e., $\mu \mathrm{m} /$ pixel) provided for the camera, lens and magnifications used was validated measuring standard circles in a reticule and standard line spacings in a grating and the agreement was better than $0.5 \%$. The traversing rail shown in the figure moved the diffuser and camera to 7 prescribed $x$-positions $(0.0013,0.030,0.059$, $0.088,0.116,0.145$ and $0.174 \mathrm{~m}$ ), while the $\mathrm{y}$ and $\mathrm{z}_{\mathrm{s}}$ positions where maintained constant at $0 \mathrm{~m}$ and $0.175 \mathrm{~m}$, respectively. Differently from the measurements with the patternator the measurements with the PDIA system were carried out with the nozzle oriented vertically downward, but it was experimentally verified that the distributions of $d_{d}$ and $u$ obtained with both orientations were not significantly different.

The water for the pneumatic nozzle was supplied from a reservoir using an immersion pump instrumented with a digital turbine flow-meter, a valve and a digital pressure gauge. A compressor provided the air and this line was instrumented with an automatically 
controlled valve, to minimize flow rate variations, a mass flow-meter and a digital manometer. The results reported in this article are for a Casterjet 1/2-6.5-90 nozzle (Spraying Systems Co., Chicago, IL), whose operating diagram is displayed in Figure 2. The conditions investigated are indicated by the triangles drawn in the plot, and it is seen that they correspond to constant $\mathrm{W}$ with different air inlet pressures, $\mathrm{p}_{\mathrm{a}}$, and vice versa.

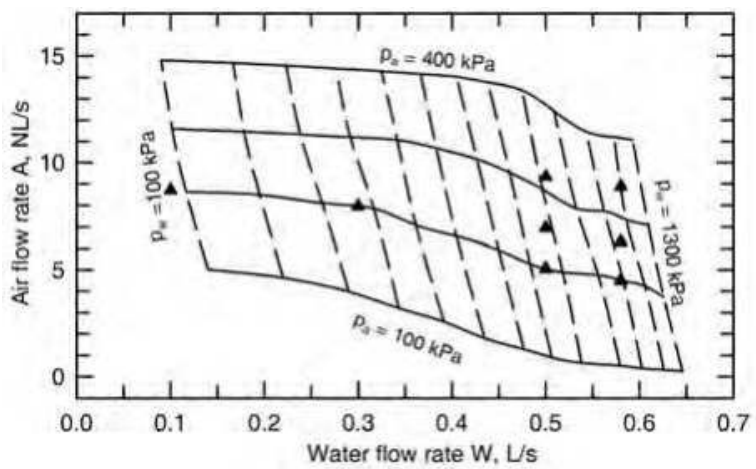

Fig. 2. Measured operating diagram of a Casterjet 1/2-6.5-90 nozzle

\section{Mathematical model and computational procedure}

\subsection{System considered and assumptions}

The 3-D system domain considered in the model is shown in Fig. 3(a), it includes the twophase free-jet issuing from a pneumatic nozzle and the surrounding environment; the mixing chamber is excluded from the analysis. Since the visualization of the jets and the

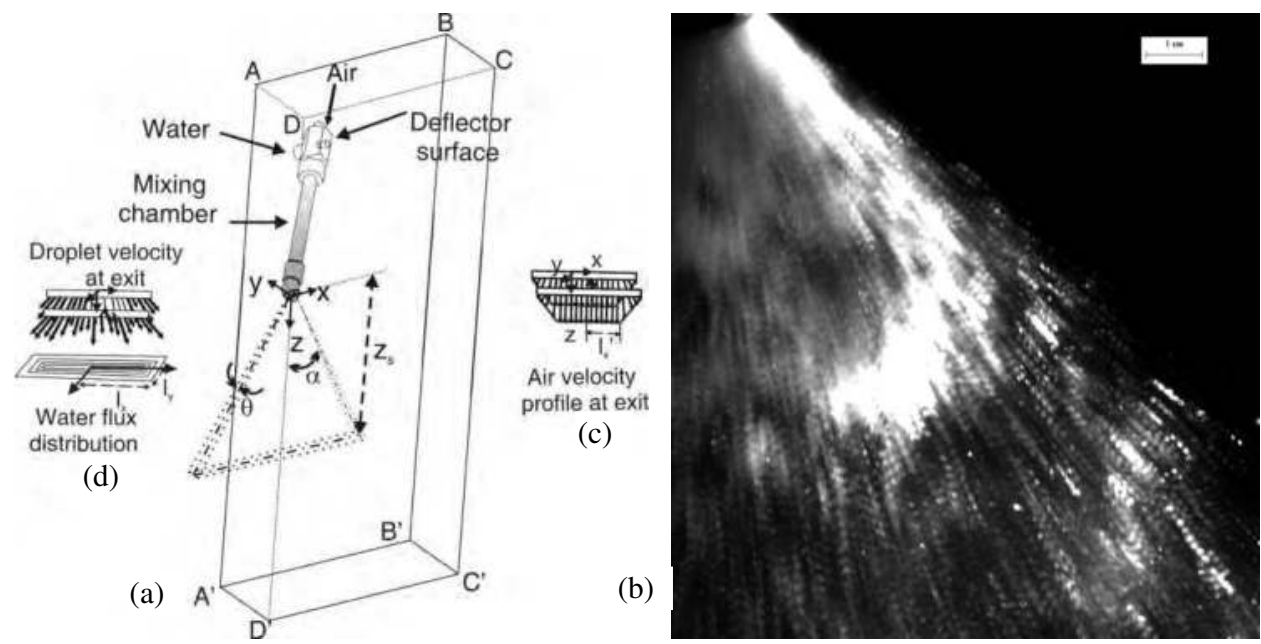

Fig. 3. (a) Schematic of system considered and computational domain, (b) quadruple exposure PIV image of drops in the neighborhood of the nozzle orifice, (c) schematic of assumed air-velocity profiles at nozzle exit and (d) schematic of assumed drop velocity profiles and water flux distribution at nozzle exit 
measurements of their impact footprints indicated double symmetry over the $x-z$ and $y-z$ planes the computational domain involved just one quarter of the physical domain, as seen in the figure. Additionally, since the air- and water-flow rates were stable it was assumed that on a time average basis, the flow characteristics of the two-phase jet could be simulated in steady-state conditions. For their treatment the continuous air-phase was considered in an Eulerian frame of reference and the discrete droplets were regarded in a Lagrangian frame.

The assumptions for the model were: (a) the liquid emerges from the nozzle as drops. This is supported by PIV observations done close of the nozzle orifice, as that displayed in Figure $3(b)$. This figure shows a quadruple-exposure photograph with trails of 4-images of droplets. Additionally and in agreement with PDIA observations the drops are assumed spherical; (b) the size distribution of the drops exiting the orifice is equal to the distribution measured at a distance $z=z_{s}$ (i.e., at the typical working distance of a given nozzle). This is reasonable since drop coalescence and break-up are rare events. The low volume fraction, $\alpha_{\mathrm{d}}$, of the drops prevents coalescence and the PDIA images, taken at different positions in the free mists, rarely show droplet break-up; (c) drops of all the specified sizes leave the orifice at the terminal velocity reached in the mixing chamber while dragged by the air. Calculations indicate that this would be the case for individual drops and since $\alpha_{\mathrm{d}}$ is low the assumption would seem reasonable for the dilute multi-drop system moving within the chamber; in the mixing chamber $\alpha_{d}<0.08$; (d) the droplets in the jet do not interact with each other and only interact with the air through interfacial drag, and (e) the air and the droplets are at room temperature and condensation and vaporization are negligible.

\subsection{Governing equations}

Under the considerations just described, the governing equations for the motion of the air are: the continuity equation (2), the Navier-Stokes equations (3) and the turbulence transport equations (4) and (5), which are expressed as follows,

$$
\begin{gathered}
\frac{\partial \mathrm{U}_{\mathrm{i}}}{\partial \mathrm{x}_{\mathrm{i}}}=0 \\
\rho \mathrm{U}_{\mathrm{i}} \frac{\partial \mathrm{U}_{\mathrm{j}}}{\partial \mathrm{x}_{\mathrm{i}}}=-\frac{\partial \mathrm{p}}{\partial \mathrm{x}_{\mathrm{j}}}+\frac{\partial}{\partial \mathrm{x}_{\mathrm{j}}}\left[\left(\mu+\mu_{\mathrm{t}}\right)\left(\frac{\partial \mathrm{U}_{\mathrm{i}}}{\partial \mathrm{x}_{\mathrm{j}}}+\frac{\partial \mathrm{U}_{\mathrm{j}}}{\partial \mathrm{x}_{\mathrm{i}}}\right)\right]+\mathrm{S}_{\mathrm{i}} \\
\rho \mathrm{U}_{\mathrm{i}} \frac{\partial \mathrm{k}}{\partial \mathrm{x}_{\mathrm{i}}}=\frac{\partial}{\partial \mathrm{x}_{\mathrm{i}}}\left[\left(\mu+\frac{\mu_{\mathrm{t}}}{\sigma_{\mathrm{k}}}\right) \frac{\partial \mathrm{k}}{\partial \mathrm{x}_{\mathrm{i}}}\right]+\mu_{\mathrm{t}}\left(\frac{\partial \mathrm{U}_{\mathrm{i}}}{\partial \mathrm{x}_{\mathrm{j}}}+\frac{\partial \mathrm{U}_{\mathrm{j}}}{\partial \mathrm{x}_{\mathrm{i}}}\right) \frac{\partial \mathrm{U}_{\mathrm{i}}}{\partial \mathrm{x}_{\mathrm{j}}}-\rho \varepsilon \\
\rho \mathrm{U}_{\mathrm{i}} \frac{\partial \varepsilon}{\partial \mathrm{x}_{\mathrm{i}}}=\frac{\partial}{\partial \mathrm{x}_{\mathrm{i}}}\left[\left(\mu+\frac{\mu_{\mathrm{t}}}{\sigma_{\varepsilon}}\right) \frac{\partial \varepsilon}{\partial \mathrm{x}_{\mathrm{i}}}\right]+\mathrm{f}_{1} \mathrm{C}_{1} \mu_{\mathrm{t}} \frac{\varepsilon}{\mathrm{k}}\left(\frac{\partial \mathrm{U}_{\mathrm{i}}}{\partial \mathrm{x}_{\mathrm{j}}}+\frac{\partial \mathrm{U}_{\mathrm{j}}}{\partial \mathrm{x}_{\mathrm{i}}}\right) \frac{\partial \mathrm{U}_{\mathrm{i}}}{\partial \mathrm{x}_{\mathrm{j}}}-\rho \mathrm{f}_{2} \mathrm{C}_{2} \frac{\varepsilon^{2}}{\mathrm{k}}
\end{gathered}
$$

$S_{i}$ in Eq. (3) is the source term expressing the i-direction momentum transferred between the air and the drops in a given cell of the fixed Eulerian grid over a Lagrangian time step. It is equal to the change in the momentum (only due to interfacial drag) of the drops following all the trajectories traversing a cell over that time step (Crowe et al., 1977) and it is given as,

$$
S_{i}=\frac{\pi \rho_{d}}{6 v_{\text {cell }}} \sum_{k=1}^{n_{\text {cell }}}\left(N_{d} d_{d}^{3}\left(u_{i, \text { out }}-u_{i, \text { in }}\right)\right)_{k}
$$


The meaning of the symbols appearing in the equations is given in Section 7 . The turbulence of the air was treated by the k- $\varepsilon$ model for low Reynolds flows of Lam-Bremhorst modified by Yap, 1987. The constants and functions appearing in Eqs. (4) and (5) are listed in Table 1. Also, under the considerations done in Sec. 3.1 the equation of motion for individual drops in the mist and under the effects of aerodynamic drag and gravity is expressed as,

$$
\frac{\mathrm{du}}{\mathrm{dt}}=\frac{3}{4} \mathrm{C}_{\mathrm{D}} \frac{\rho}{\rho_{\mathrm{d}} \mathrm{d}_{\mathrm{d}}}\left|\mathrm{U}_{\mathrm{i}}-\mathrm{u}_{\mathrm{i}}\right|\left(\mathrm{U}_{\mathrm{i}}-\mathrm{u}_{\mathrm{i}}\right)+\left(1-\frac{\rho}{\rho_{\mathrm{d}}}\right) \mathrm{g}_{\mathrm{i}}
$$

The drag coefficient $C_{D}$ was assumed to vary with the particle Reynolds number, $R_{d}$, according to the expressions given in Table 1. The trajectory of the drops was computed from the variation with time of the components of the position-vectors, according to,

$$
\frac{d x_{i}}{d t}=u_{i}
$$

\begin{tabular}{|} 
Constants and functions involved in the turbulence model \\
\hline $\mathrm{C}_{1}=1.44 ; \mathrm{C}_{2}=1.92 ; \mathrm{C}_{\mathrm{d}}=0.09 ; \sigma_{\mathrm{k}}=1.0 ; \sigma_{\mathrm{\varepsilon}}=1.3$ \\
$f_{\mu}=\left(1-\exp \left(-0.0165 \operatorname{Re}_{z^{\prime}}\right)\right)^{2}\left(1+\frac{20.5}{\operatorname{Re}_{t}}\right) ; f_{1}=1+\left(\frac{0.05}{f_{\mu}}\right)^{3} ; f_{2}=1-\exp \left(-\operatorname{Re}_{t}^{2}\right)$ where, \\
$\mu_{\mathrm{t}}=\rho_{\mu} \mathrm{C}_{\mathrm{d}} \frac{\mathrm{k}^{2}}{\varepsilon} ; \operatorname{Re}_{\mathrm{z}^{\prime}}=\frac{\sqrt{\mathrm{k} \mathrm{z}^{\prime}}}{\mathrm{v}} ; \operatorname{Re}_{\mathrm{t}}=\frac{\mathrm{k}^{2}}{\mathrm{v} \varepsilon}$
\end{tabular}

${ }^{*} \mathrm{~A}$ is computed at local conditions: $25^{\circ} \mathrm{C}, 86 \mathrm{kPa}$.

Table 1. Auxiliary equations, properties and dimensions 


\subsection{Boundary and initial conditions}

At the boundaries of the calculation domain shown in Fig. 3(a), Eqs. (2) through (5) describing the turbulent motion for the air-phase were solved imposing the following conditions:

- Ambient conditions at boundaries $\mathrm{ABCD}, \mathrm{A}^{\prime} \mathrm{B}^{\prime} \mathrm{C}^{\prime} \mathrm{D}^{\prime}, \mathrm{ABB} \mathrm{A}^{\prime}$ and $\mathrm{BC} \mathrm{C}^{\prime} \mathrm{B}^{\prime}$, specified as,

$$
\mathrm{P}=\mathrm{P}_{\mathrm{amb}} ; \mathrm{k}=\mathrm{e}=0
$$

To approach these conditions, the boundaries were located far away from the jet.

- Symmetry conditions at the boundaries ADD'A', DCC'D', given as:

$$
U_{j}=\frac{\partial U_{i}}{\partial x_{j}}=\frac{\partial k}{\partial x_{j}}=\frac{\partial \varepsilon}{\partial x_{j}}=0
$$

where $\mathrm{j}$ represents the index for the coordinate normal to the respective symmetry plane.

- Non-penetration and non-slip conditions were specified at the external wall of the nozzle,

$$
\mathrm{U}_{\mathrm{i}}=\mathrm{k}=\varepsilon=0
$$

- $\quad$ Air velocity profiles as those shown in Fig. 3(c) were specified at the nozzle orifice, which corresponds to an internal boundary. Along the $x$-direction these profiles were uniform over the length $l_{x}^{\prime}$ of the flat hollow portion of the flanged orifice, in the rest of the orifice the profiles decreased to zero varying in angle from 0 deg to $\alpha$ deg at the edge; the distributions were the same throughout the whole thickness (y-)direction of the orifice. These velocity profiles were suggested by the geometry of the flanged orifice and are supported by the results presented in Section 4 . The expressions describing the profiles are listed in Table 1, together with the expressions for the turbulence kinetic energy and the dissipation rate of turbulence kinetic energy at this boundary, $\mathrm{k}_{\mathrm{o}}$ and $\varepsilon_{\mathrm{o}}$, respectively.

- Positions and velocities were specified to the droplets as initial conditions for the solution of their motion (7) and trajectory (8) equations. For doing this, a first step was to decide a series of criteria to distribute throughout the orifice drops of different size and velocity in a random fashion that reflected that the water flux profile decreases from its center to its edges. To do this, the orifice was simulated as a grid of ports, $k$, releasing drops satisfying the diameter distribution measured at $\mathrm{z}=\mathrm{z}_{\mathrm{s}}$ (according with the assumption indicated in Section 3.1) for the particular set of nozzle operating conditions under consideration. For deciding the number of ports assigned to each drop size category it is important to establish what type of distribution to use, number or volume frequency? Figure 4 shows both size distributions measured for a representative set of operating conditions $\mathrm{W}$ and $\mathrm{p}_{\mathrm{a}}$. The number frequency distribution shows that droplets smaller than $25 \mu \mathrm{m}$ account for a large number percentage of the drops ( $82.85 \%$ of them), but that they represent only $6.82 \%$ of the volume of the drops in the sample. Since the number of ports that can be used cannot be excessively large the assignment of the ports according to the number frequency distribution would leave many sizes unrepresented. The volume frequency distribution does not present this disadvantage and was chosen to designate the number of ports for each size category. The size assigned to each port was done through a random number generator to simulate the stochastic emergence of drops with different characteristics from distinct sites of the orifice. The drops with volume $v_{d, k}=\left(\pi d_{d}\right)_{k} / 6$ exiting the ports $\mathrm{k}$ with a number frequency, $\mathrm{N}_{\mathrm{d}, \mathrm{k}}$, had to satisfy the water-flow rate, $\mathrm{W}$, according to the following expression, 


$$
W=\sum_{k=1}^{n_{T}} N_{d, k} v_{d, k}
$$

Furthermore, based on the form of the mist footprint obtained with a patternator the water flow was assumed to be distributed in the orifice according to an obelisk-shaped distribution (Camporredondo et al., 2004), as that shown schematically in Figure 3(d).

With the criteria given, the initial conditions for Eqs. (7) and (8) were assigned to each port of the nozzle orifice, such that at $t=0$ the position and velocity of the drop are specified as follows,

$$
\mathrm{u}_{\mathrm{i}}=\left(\mathrm{u}_{\mathrm{i}}\right)_{\mathrm{k}} \text { and } \mathrm{x}_{\mathrm{i}}=\left(\mathrm{x}_{\mathrm{i}}\right)_{\mathrm{k}}
$$

As mentioned in Sec. 3.1, the initial velocity, $\left(\mathrm{u}_{\mathrm{i}}\right)_{\mathrm{k}}$, of the drops was prescribed by assuming that the drops exit with the terminal velocity that they reach in the mixing chamber (Minchaca et al., 2010). As suggested by the observed drop trajectories (Hernández et al., 2008), according to the position assigned to the drop the angle of the velocity varied from 0 $\operatorname{deg}$ to $\alpha$ deg in the $x$-direction and from 0 deg to $\theta$ deg in the y-direction. A schematic representation of the velocity vectors of the drops is displayed in Fig. 3(d), and the expressions for the $u_{x, k}, u_{y, k}$ and $u_{z, k}$ velocity components are given in Table 1 . Also, the physical properties of the fluid, the dimensions of the orifice and the angles of expansion of the jet are given in the table.

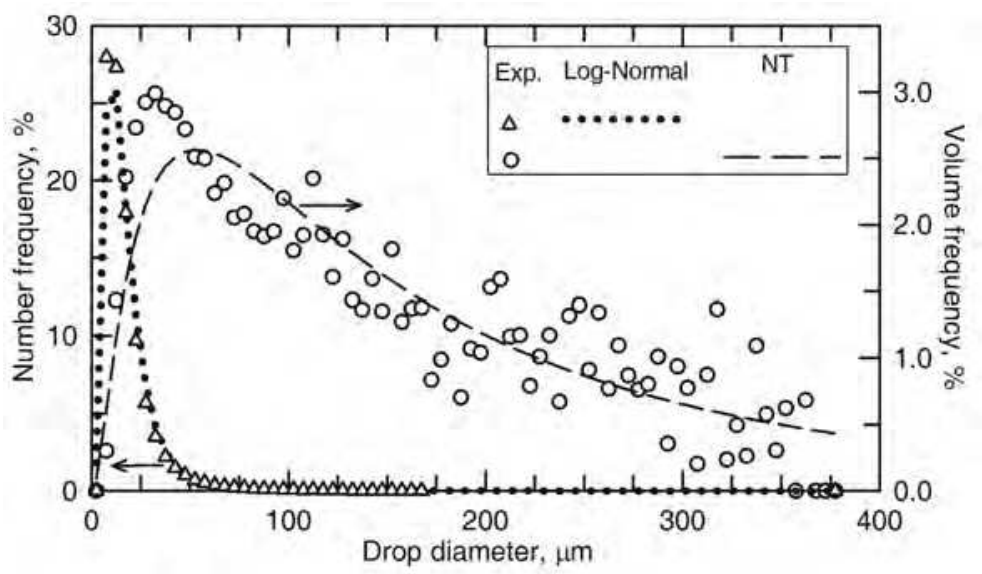

Fig. 4. Numeric and volume frequency drop size distributions measured for $\mathrm{W}=0.58 \mathrm{~L} / \mathrm{s}$ and $p_{a}=279 \mathrm{kPa}$. The log-normal and Nukiyama-Tanasawa, NT, distributions fitted to the respective data are included

\subsection{Solution procedure}

The Eulerian and Lagrangian equations of the model were solved using the control volume method and the particle tracking facility implemented in Phoenics. The mesh used had $128 \times 25 \times 99$ control volumes to achieve mesh independent results and the number of ports was $100 \times 12$ in the $x-y$ directions. The convergence criterion specified a total residual for all the dependent variables $\leq 10^{-3}$. 


\section{Experimental and computational results and discussion}

\subsection{Drop velocity and size correlation}

As indicated in Sec. 2 the drop size and velocity measurements were done at 7 sampling volumes spaced along the $\mathrm{x}$-direction at $\mathrm{y}=0$ and $\mathrm{z}=\mathrm{z}_{\mathrm{s}}$. Figure 5 shows the correlation between drop velocity and diameter for the set of measurements done over all the sampling volumes. Droplets of all sizes exhibit a wide range of velocities when they arrive to the measuring positions. It is noticed that as the droplet diameter decreases their velocities exhibit a broader range, many small drops arrive at the measuring axis with small velocities and this causes a weak positive correlation between droplet velocity and diameter, i.e., the results denote a slight trend in the velocities to be larger as the size of the drops increases. Correlation coefficients, for several conditions and positions, were evaluated quantitatively in another work and confirm the weak positive correlation appreciated for the particular case illustrated in the figure (Minchaca et al., 2011).

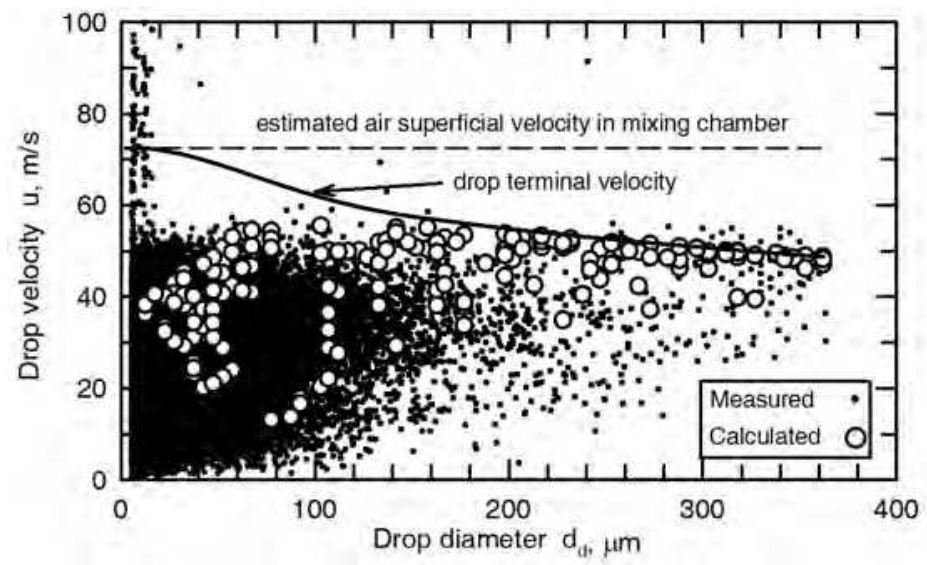

Fig. 5. Measured and calculated velocities for drops of different sizes reaching the $x$-axis at $\mathrm{y}=0$ and $\mathrm{z}=\mathrm{z}_{\mathrm{s}}$. The results are for $\mathrm{W}=0.58 \mathrm{~L} / \mathrm{s}$ and $\mathrm{p}_{\mathrm{a}}=279 \mathrm{kPa}$

Figure 5 also shows results of computed velocities for drops arriving at the measuring axis. In agreement with the experiments, the results of the model reveal that the small drops exhibit a broader spectrum of velocities than the larger ones, causing the development of a weak positive correlation of velocity with size. Considering that the model assumes that all drops of each size leave the nozzle at the particular terminal velocity that they reach in the mixing chamber, as a result of the drag exerted by the air, the results of the figure indicate that the smaller droplets are more susceptible to lose their momentum while moving in the mist jet interacting with the air. This is evidenced by comparing the dispersion results with the calculated terminal velocity curve included in the figure. From the nozzle exit the drops follow ballistic nearly rectilinear trajectories and drops of the same size, which according to the model exit at the same velocity, will decelerate more when leaving from external than from internal positions of the nozzle orifice, so that they travel in the periphery of the jet interacting with the quiescent environment. This statement is supported by the experimental and computational results displayed in Fig. 6, which shows the variation of the normal and tangential velocity components of drops of different size traversing the sampling volumes 
located at the different $x$-positions. The regression curves fitted to the experimental and computational results show an excellent agreement. The dispersion exhibited by the computed results displayed in Figs. 5 and 6 is smaller than the experimental due to the very different number of drop trajectories traversing the sampling volumes, thousands in the experimental case versus a few tens in the computational case. Despite of this the model is able to represent very well the trend in the behavior of the actual system.

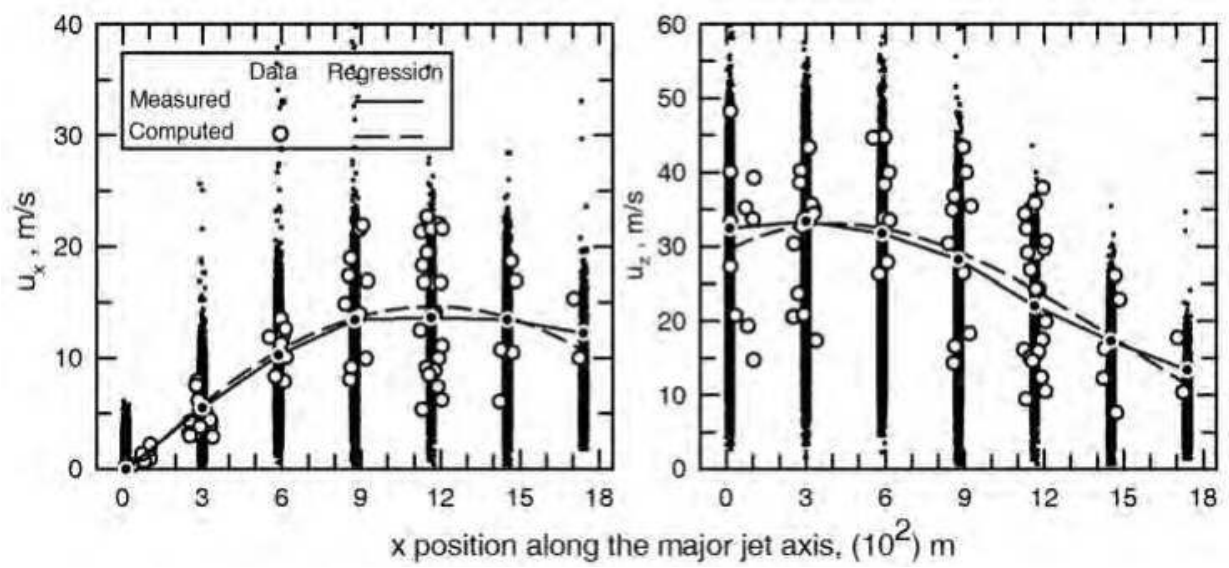

(a)

(b)

Fig. 6. Measured and computed velocity components as a function of $x$-position for drops of all sizes: (a) tangential velocity component and (b) normal velocity component. The results are for $\mathrm{W}=0.58 \mathrm{~L} / \mathrm{s}$ and $\mathrm{p}_{\mathrm{a}}=279 \mathrm{kPa}$

\subsection{Effect of nozzle operating conditions on the velocity of the drops 4.2.1 Effect of water flow rate at constant air inlet pressure}

In the application of air-mist nozzles for the cooling of surfaces at high temperature it is common to vary the water flow rate maintaining constant the air inlet pressure. This procedure would be equivalent to move along the curves of constant $p_{a}$ appearing in the operating diagram of Figure 2. The reason behind this is that the spray cooling intensity is commonly associated only to the flux of water impinging upon the hot surface, when actually there is another mist parameter that plays an important role and this is the velocity of the drops (Hernández et al., 2011). Experimentally, it has been found that the velocity of the drops increases with $W$ up to a certain value, but once this value is exceeded the opposite effect takes place and the drop velocity decreases markedly (Minchaca et al., 2011). With the increase in $\mathrm{W}$ at constant $\mathrm{p}_{\mathrm{a}}$ the drops generated by the nozzle become larger (Minchaca et al., 2011) and the air flow rate, A, gets smaller as indicated by Figure 2. Both factors will alter the terminal velocities that the drops will reach at the nozzle exit and also their behavior in the free jet.

The multivariate effects that the droplet velocity experiences when changing $\mathrm{W}$ at constant $\mathrm{p}_{\mathrm{a}}$ are complex. Therefore, it was important to examine the predictions of the CFD model in 
this regard. Figure 7 shows experimental and computational profiles of the normal and tangential volume weighed mean velocity components defined as,

$$
\mathrm{u}_{\mathrm{z}, \mathrm{v}}=\sum_{\mathrm{i}=1}^{\mathrm{N}} \mathrm{u}_{\mathrm{z}, \mathrm{i}} \mathrm{d}_{\mathrm{d}, \mathrm{i}}^{3} / \sum_{\mathrm{i}=1}^{\mathrm{N}} \mathrm{d}_{\mathrm{d}, \mathrm{i}}^{3} ; \mathrm{u}_{\mathrm{x}, \mathrm{v}}=\sum_{\mathrm{i}=1}^{\mathrm{N}} \mathrm{u}_{\mathrm{x}, \mathrm{i}} \mathrm{d}_{\mathrm{d}, \mathrm{i}}^{3} / \sum_{\mathrm{i}=1}^{\mathrm{N}} \mathrm{d}_{\mathrm{d}, \mathrm{i}}^{3}
$$

for four different water flow rates and a constant $p_{a}=205 \mathrm{kPa}$. It is seen that both, experimental and computational results, indicate that the increase in $\mathrm{W}$ from 0.1 to $0.3 \mathrm{~L} / \mathrm{s}$ causes an increase in the normal and tangential velocity components and that further increase leads to a decrease in the velocities. The drop velocities obtained with $\mathrm{W}$ equal to $0.30 \mathrm{~L} / \mathrm{s}$ and $0.58 \mathrm{~L} / \mathrm{s}$ are considerably different, being substantially smaller for the higher $\mathrm{W}$. This behavior could be one of the factors of why the heat transfer does not augment considerably when $\mathrm{W}$ and hence $\mathrm{w}$ do it (Montes et al., 2008). The computed velocities are somewhat larger than the experimental because the volume frequency distribution of sizes, chosen to establish the model, generates a greater number of large drops than small drops.

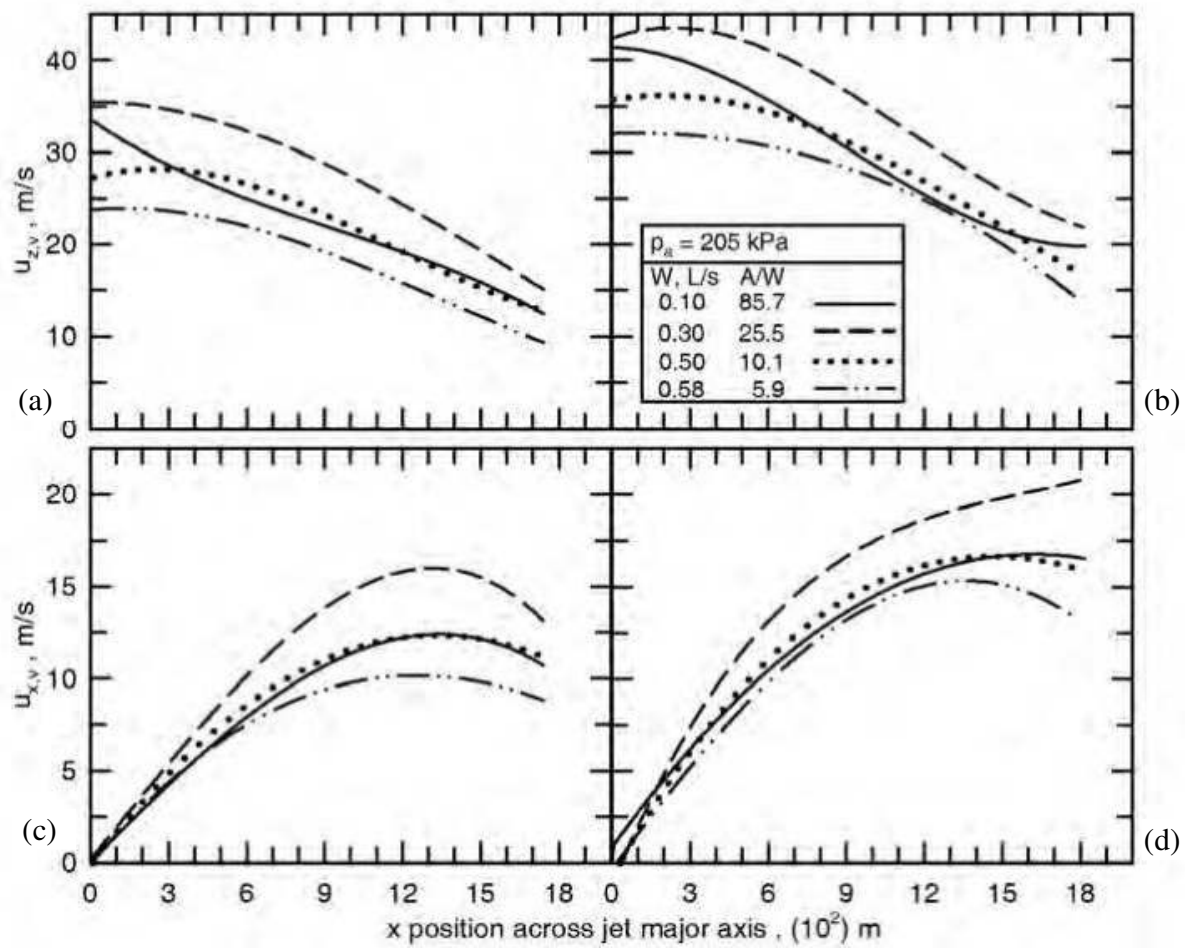

Fig. 7. Measured and computed volume weighed mean velocity components as a function of $x$-position for different $\mathrm{W}$ and a constant $\mathrm{p}_{\mathrm{a}}$. Normal velocity components: (a) measured, (b) computed. Tangential velocity components: (c) measured, (d) computed 


\subsubsection{Effect of air inlet pressure at constant water flow rate}

The computed and measured $\mathrm{x}$ - and $\mathrm{z}$-components of the volume weighed mean velocity are shown in Fig. 8, for conditions involving a constant $W$ and different $p_{a}$. The agreement between computed and experimental results is quite reasonable and the curves show that as $\mathrm{p}_{\mathrm{a}}$ increases both velocity components become larger. This behavior suggests that if the drops were to impinge over a surface, a more intimate contact would take place as $p_{a}$ increases; this as a consequence of the higher impingement Weber numbers that would result. The larger tangential velocity component of the drops hints a faster renewal of the liquid on the surface as $p_{a}$ increases. In fact, heat transfer experiments have shown a substantial increase in the heat flux with the increase in $\mathrm{p}_{\mathrm{a}}$ at constant W (Montes et al., 2008; Hernández et al., 2011), suggesting that the change in the fluid dynamic behavior of the drops with the increase in $p_{a}$ favors heat transfer. The phenomena occurring during the impingement of dense air-mist jets with solid surfaces is being investigated. The effect of $p_{a}$ on the intensity of heat extraction could have important implications to achieve water savings during cooling operations. Similar to the results in Fig. 7, the computed velocities in Fig. 8 are somewhat larger than the experimental because the volume frequency distribution of sizes tends to generate a greater number of large drops than small drops.

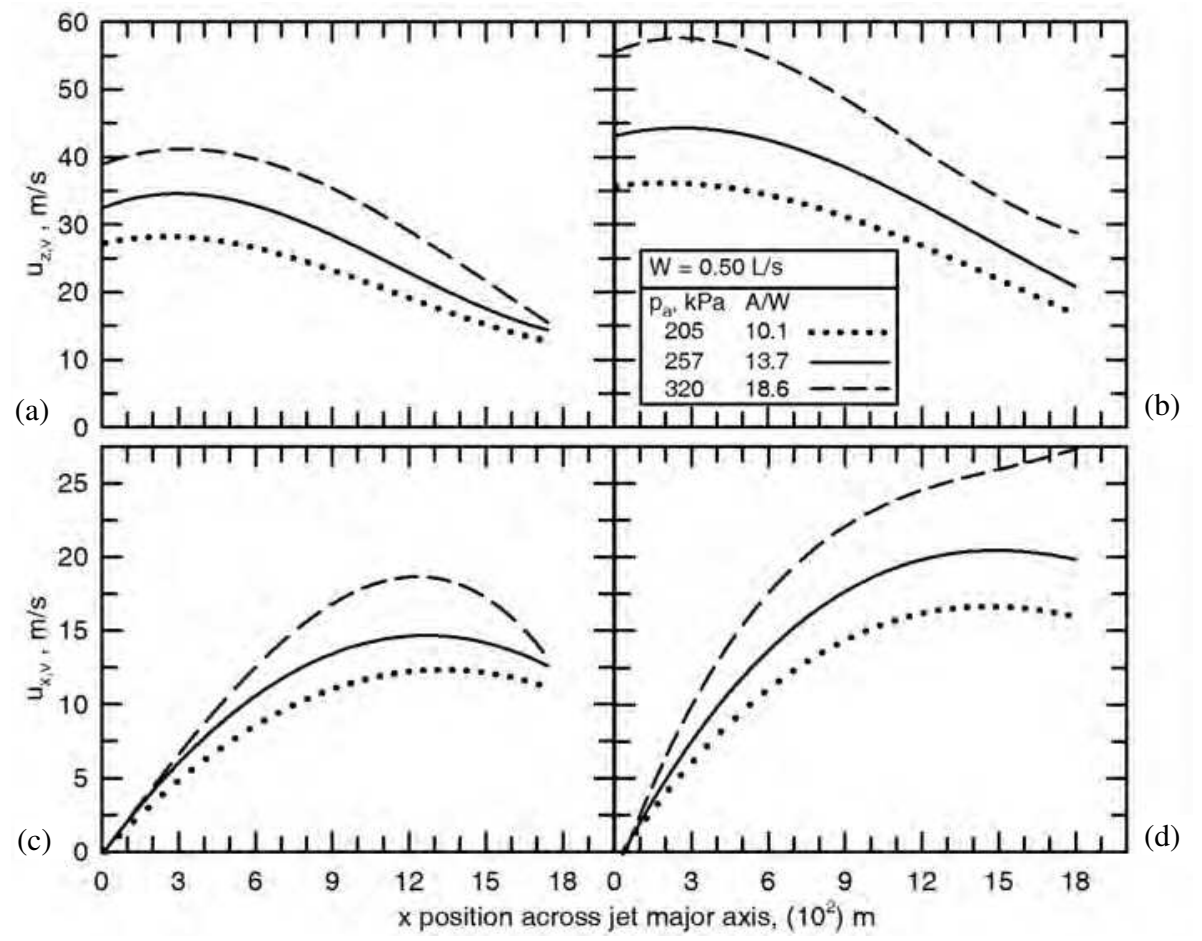

Fig. 8. Measured and computed volume weighed mean velocity components as a function of $x$-position for different $p_{a}$ and constant $W$. Normal velocity components: (a) measured, (b) computed. Tangential velocity components: (c) measured, (d) computed 


\subsection{Effect of air inlet pressure on droplet volume fraction and water impact flux}

As mentioned in Sec. 1 the mists have been classified in dense or dilute according to the value of the water impact density. However, little has been investigated about the actual mist density defined as the volume of liquid of the drops per unit volume of space; which is equivalent to the local liquid volume fraction, $\alpha_{\mathrm{d}}$. This parameter would give an indication of how critical could be to the model the assumption that the drops in the free jet do not interact as a consequence that they are far apart from each other. Although, the direct experimental measurement of this parameter is difficult the validity of the computational estimation of $\alpha_{d}$ can be tested by its relation with the water impact density. The local water volume fraction can be defined by the following expression,

$$
\alpha_{\mathrm{d}}=\frac{\sum_{\mathrm{k}=1}^{\mathrm{n}_{\text {cell }}}\left(\mathrm{N}_{\mathrm{d}} \mathrm{v}_{\mathrm{d}} \Delta \mathrm{t}\right)_{\mathrm{k}}}{\mathrm{v}_{\text {cell }}}
$$

and the water impact density can be evaluated as,

$$
w(x, y)=\frac{\sum_{k=1}^{n_{A}}\left(N_{d} v_{d}\right)_{k}}{A(x, y)}
$$

Figure 9 shows computed contour plots of $\alpha_{d}$ over the $x-z$ symmetry plane of mist jets generated with a constant water flow rate and different air nozzle pressures. It is appreciated that as the air inlet pressure decreases the region close to the nozzle exhibits a higher liquid fraction. This behavior arises from the larger size and smaller velocities of the drops generated as $p_{a}$ decreases. For conservation of mass this last factor would imply that

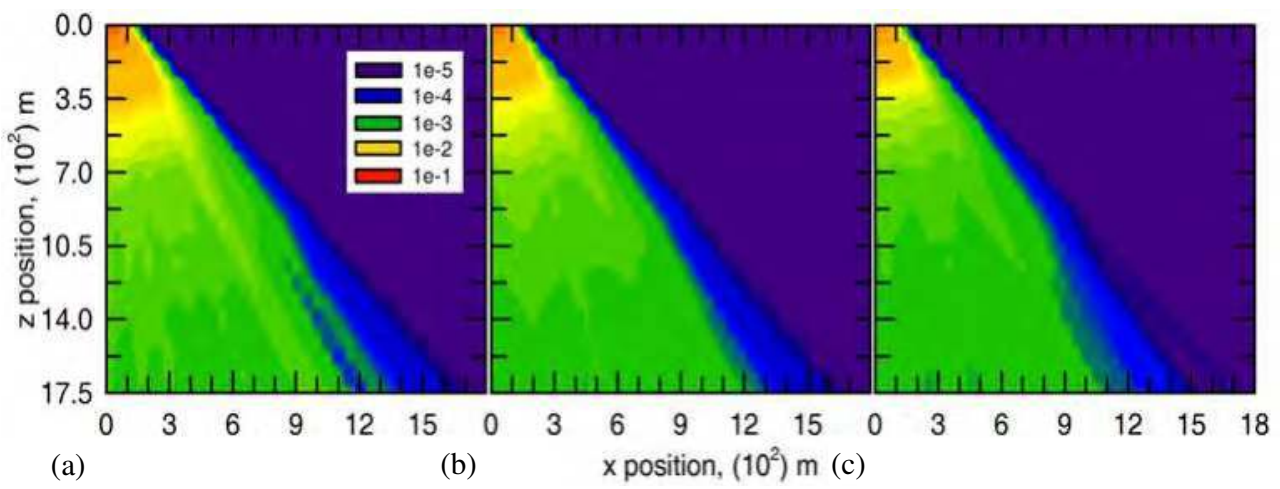

Fig. 9. Computed contour maps of $\alpha_{d}$ over the main symmetry plane of the mist jet for a $W=$ $0.50 \mathrm{~L} / \mathrm{s}$ and $\mathrm{p}_{\mathrm{a}}$ of: (a) $205 \mathrm{kPa}$, (b) $257 \mathrm{kPa}$ and (c) $320 \mathrm{kPa}$ 
the drops travel more closely spaced as $p_{a}$ decreases, leading this to a higher particle packing. This behavior continues up to $z=z_{s}$ where regions of higher liquid volume fraction are more widely spread in the case of smaller $\mathrm{p}_{\mathrm{a}}$.

The predicted liquid fraction contours indicate that the increase in $\mathrm{p}_{\mathrm{a}}$ at constant $\mathrm{W}$ causes a redistribution of the liquid in the free jet that could affect the water impact density. In previous w measurements no effect was detected (Hernández et al., 2008). Thus, it was decided to refine the patternator to try to reveal if there was an influence of $p_{a}$ on the water impact density for a constant $\mathrm{W}$. Figure 10 shows measured and computed water impact density maps for $\mathrm{p}_{\mathrm{a}}$ of $257 \mathrm{kPa}$ and $320 \mathrm{kPa}$ with $\mathrm{W}=0.50 \mathrm{~L} / \mathrm{s}$. It is seen that both results agree very well and indicate an increase of the water impact density with the increase in $\mathrm{p}_{\mathrm{a}}$, in the central region. Based on the model, this result points out that although at higher $\mathrm{p}_{\mathrm{a}}$ the drops tend to travel more widely spaced from each other, having a lower volume fraction, their higher velocities causes them to arrive more frequently to the collecting cells of the patternator or equivalently to the virtual impingement plane (in the case of the model), leading this to higher $\mathrm{w}$ in the central region of the footprint. The differences observed in the figure between experimental and computed results are mainly in the sizes of the footprint. This discrepancy arises because the model considers the nominal value of the expansion semi-angle $\alpha$ and a semi-angle $\theta=$ $10 \mathrm{deg}$. However, the $\mathrm{w}$ maps and the visualization of the jets indicate that the actual angles were slightly larger than the nominal values.

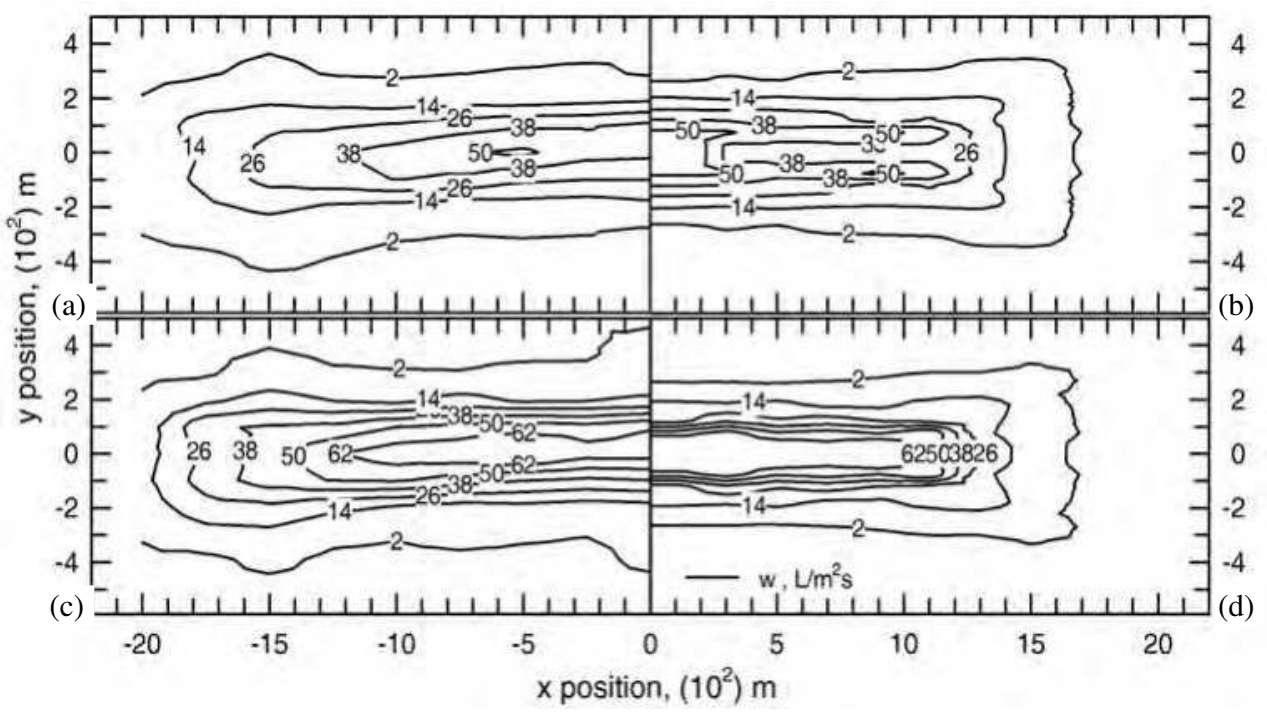

Fig. 10. Contour maps of $w$ at $z=z_{s}$ for a $W=0.50 \mathrm{~L} / \mathrm{s}$ with $\mathrm{p}_{\mathrm{a}}=257 \mathrm{kPa}$ : (a) experimental, (b) computational and with $\mathrm{p}_{\mathrm{a}}=320 \mathrm{kPa}$ (c) experimental, (d) computational 


\section{Summary and conclusions}

A comprehensive experimental and computational study of the fluid dynamics of air-mist jets generated under conditions of interest in the cooling of surfaces found in metallurgical processes and in other high temperature processes was carried out. The work analyzes the variation of droplet velocity and water impact density as a function of droplet size and nozzle operating conditions.

The rigorous determination of statistically meaningful samples of droplet size allowed to establish that a relatively small numeric proportion ( 0.17) of 'large' drops (between $\sim 25 \mu \mathrm{m}$ and $370 \mu \mathrm{m})$ are responsible for transporting a large fraction of the water in the mist. The smaller drops transport only a small proportion of the liquid volume. This fact, which is typical of the different nozzles and operating conditions, suggested that the description of the drop sizes mainly responsible for carrying the water arriving at a given distance from the nozzle orifice would be crucial for formulating a 3-D turbulent Eulerian-Lagrangian model for simulating the dynamics of fan-shaped air-mists. Thus, the present model considers the volume frequency distribution of sizes, instead of the number frequency distribution, to prescribe the inlet ports assigned to the different sizes. This specification, together with those for the distributions of the velocity of the air and drops and of the water volume flux at the orifice, was critical in the results of the model.

The model predicts very well the correlation between drop velocity and size, indicating that the finest drops tend to decelerate rapidly when traveling in the periphery of the mist. Also, it gives an accurate description of the influence that the variation in water flow rate at constant air inlet pressure, and of the variation in air inlet pressure at constant water flow rate, has on the velocity of the drops and on the water impact density distribution. The results on the fluid dynamics of free mist jets are being very useful to develop models for simulating the interaction of dense mists with solid surfaces.

\section{Acknowledgments}

The authors are grateful to the National Council of Science and Technology of Mexico (CONACYT) for financial support through grant No. 57836. JIMM wish to thank CONACYT for his Ph.D scholarship grant.

\section{Nomenclature}

a

A

$\mathrm{A}(\mathrm{x}, \mathrm{y})$

$\mathrm{C}_{1}, \mathrm{C}_{2}, \mathrm{C}_{\mathrm{d}}$

$\mathrm{C}_{\mathrm{D}}$

$\mathrm{d}_{\mathrm{d}}$

$\mathrm{f}_{\mu}, \mathrm{f}_{1}, \mathrm{f}_{2}$

$\mathrm{g}$

$\mathrm{k}, \mathrm{k}_{\mathrm{o}}$
Area of collector tube in patternator, $\mathrm{m}^{2}$

Air flow rate at normal conditions (i.e., $0^{\circ} \mathrm{C}, 101.3 \mathrm{kPa}$ ), $\mathrm{NL} \mathrm{s}^{-1}$, or ambient conditions $\left(25^{\circ} \mathrm{C}, 86 \mathrm{kPa}\right), \mathrm{L} \mathrm{s}^{-1}$

Local area in impact plane centered around coordinates $\mathrm{x}, \mathrm{y}$.

Constants in the turbulence model

Drag coefficient

Drop diameter, $\mathrm{m}$

Functions defined in Table 1

Acceleration due to gravity, $\mathrm{m} \mathrm{s}^{-2}$

Turbulence kinetic energy; at nozzle orifice, $\mathrm{m}^{2} \mathrm{~s}^{-2}$ 
$1_{x}, 1_{y}, 1_{x}^{\prime}$

$\mathrm{n}$

$\mathrm{n}_{\mathrm{p}}$

$\mathrm{N}_{\mathrm{d}}$

p, P

$\mathrm{p}_{\mathrm{a}}, \mathrm{p}_{\mathrm{w}}$

$\operatorname{Re}_{\mathrm{d}}, \operatorname{Re}_{\mathrm{t}}, \operatorname{Re}_{\mathrm{z}^{\prime}}$

$\mathrm{S}$

$\mathrm{t}$

$\mathrm{T}_{\mathrm{S}}$

$T_{w}$

$\mathrm{u}$

$\mathrm{u}_{\mathrm{x}, \mathrm{v}}, \mathrm{u}_{\mathrm{z}, \mathrm{v}}$

$\mathrm{u}_{\mathrm{zs}}$

U

$\mathrm{U}_{z, \max }$

$\mathrm{v}$

$\mathrm{v}_{\mathrm{d}}$

W

W

$\mathrm{We}_{\mathrm{zs}}$

$x$

$x, y, z$

$\mathrm{z}_{\mathrm{s}}$

Greek symbols

$\alpha, \theta$

$\alpha_{\mathrm{d}}$

$\gamma$

$\Delta \mathrm{t}$

$\varepsilon ; \varepsilon_{o}$

$\mu, \mu_{t}$

$v$

$\rho, \rho_{\mathrm{d}}$

$\sigma$

$\sigma_{\mathrm{k}}, \sigma_{\varepsilon}$

Subscripts

$\mathrm{amb}$

cell

$\mathrm{i}, \mathrm{j}$

in, out

$\mathrm{k}$

$\max$
Half length; half width nozzle orifice; half length of hollow portion of nozzle orifice, $\mathrm{m}$

Number of drop trajectories

Port number or number of ports

Number frequency of drops, $\mathrm{s}^{-1}$

Pressure in Ecs. (3); in Eq. (9), $\mathrm{kPa}$

Air-; water nozzle inlet pressures, $\mathrm{kPa}$

Reynolds number defined in Table 1

Source term for momentum transfer interaction between the drops and the air, $\mathrm{m} \mathrm{s}^{-2}$

Time, s

Saturation temperature of water, ${ }^{\circ} \mathrm{C}$

Surface temperature, ${ }^{\circ} \mathrm{C}$

Velocity of drops, $\mathrm{m} \mathrm{s}^{-1}$

Tangential; normal volume weighed mean velocity, $\mathrm{m} \mathrm{s}^{-1}$

Normal drop velocity at $\mathrm{z}=\mathrm{z}_{\mathrm{s}}, \mathrm{m} \mathrm{s}^{-1}$

Velocity of the continuous phase (air), $\mathrm{m} \mathrm{s}^{-1}$

Velocity of air phase defined in Table 1

Volume of water collected in bottles of patternator, L; volume, $\mathrm{m}^{3}$

Volume of drop, $\mathrm{m}^{3}$

Water impact flux or water impact density, $\mathrm{L} \mathrm{m}^{-2} \mathrm{~s}^{-1}$

Water flow rate, $\mathrm{L} \mathrm{s}^{-1}$

Impinging droplet Weber number

Coordinate, $\mathrm{m}$

Rectangular coordinates, $\mathrm{m}$

Setback distance of nozzle tip from plane of interest, $\mathrm{m}$

Jet expansion half angles in $\mathrm{x}$ and $\mathrm{y}$ directions, deg

Volume fraction of drops, dimensionless

Angle defined in Eq. (1)

Time interval, $\mathrm{s}$

Dissipation rate of turbulence kinetic energy; at nozzle orifice, $\mathrm{m}^{2} \mathrm{~s}^{-3}$

Continuous-phase molecular; turbulent dynamic viscosity, Pa s

Kinematic viscosity, $\mathrm{m}^{2} \mathrm{~s}^{-1}$

Continuous; discontinuous-phase density, $\mathrm{kg} \mathrm{m}^{-3}$

Surface tension of drop phase, $\mathrm{N} \mathrm{m}^{-1}$

Laminar and turbulent Schmidt numbers for $\mathrm{k}$ and $\varepsilon$

Ambient conditions, $\mathrm{P}=86 \mathrm{kPa}, \mathrm{T}=25^{\circ} \mathrm{C}$

Discretization cell

Indexes for coordinate directions

Input, output to control volume

Ports or trajectories

Maximum 


$\begin{array}{ll}\mathrm{t} & \text { terminal } \\ \mathrm{T} & \text { Total } \\ \mathrm{x}, \mathrm{y}, \mathrm{z} & \text { Coordinates directions }\end{array}$

\section{References}

Araki, K. \& Moriyama, A. (1981). Theory on Deformation Behavior of a Liquid Droplet Impinging onto Hot Metal Surface. Transactions of the Iron and Steel Institute of Japan, Vol. 21, No. 8, (n.d. 1981), pp. 583-590, ISSN 0021-1583.

Babinsky, E. \& Sojka, P. (2002). Modeling Drop Size Distributions. Progress in Energy and Combustion Science, Vol. 28, No. 4, (February 2002), pp. 303-329.

Beck, J. \& Watkins, A. (2002). On the Development of Spray Submodels Based on Droplet Size Moments. Journal of Computational Physics, Vol. 182, No. 2, (November 2002), pp. 586-621.

Bendig, L., Raudensky, M. \& Horsky, J. (1995). Spray parameters and heat transfer coefficients of spray nozzles for continuous casting, Proceedings of Seventy-eighth Steelmaking Conference, Warrendale, PA, USA, April 2-5, 1995.

Bowen, I. \& Davies, G. (1951). Technical Report ICT 28. Shell Research Ltd., London, 1951.

Bul, Q. (2001). Development of a Fan Spray Nozzle for Continuous Caster Secondary Cooling. AISE Steel Technology, Vol. 78, No. 5, (May 2001), pp. 35-38.

Camporredondo, J., Castillejos, A., Acosta, F., Gutiérrez, E. \& Herrera, M. (2004). Analysis of Thin Slab Casting by the Compact-Strip Process: Part 1. Heat Extraction and Solidification. Metallurgical and Materials Transactions B, Vol. 35B, No. 3, (June 2004), pp. 541-560.

Ciofalo, M., Caronia, A., Di Liberto, M. \& Puleo, S. (2007). The Nukiyama Curve in Water Spray Cooling: Its Derivation from Temperature-time Histories and Its Dependence on the Quantities that Characterize Drop Impact. International Journal of Heat and Mass Transfer, Vol. 50, No. 25-26, (December 2007), pp. 4948-4966.

Crowe, C., Sharma, M. \& Stock, D. (1977). The Particle-Source-In-Cell (PSI-CELL) Model for Gas-Droplet Flows. Journal of Fluids Engineering, Vol. 99, No. 2, (June 1977), pp. 325-332.

Crowe, C., Schwarzkopf, J., Sommerfeld, M. \& Tsuji, Y. (1998). Multiphase Flows with Droplets and Particles, CRC Press LLC, ISBN 0-8493-9469-4. Boca Raton, FL, USA.

Deb, S. \& Yao, S. (1989). Analysis on Film Boiling Heat Transfer of Impacting Sprays. International Journal of Heat and Mass Transfer, Vol. 32, No. 11, (March 1989), pp. 2099-2112.

Hatta, N., Fujimoto, H., Ishii, R. \& Kokado, J. (1991a). Analytical Study of Gas-Particle TwoPhase Free Jets Exhausted from a Subsonic Nozzle. ISIJ International, Vol. 31, No. 1, (n.d. 1991), pp. 53-61, ISSN 0915-1559.

Hatta, N., Fujimoto, H. \& Ishii, R. (1991b). Numerical Analysis of a Gas-Particle Subsonic Jet Impinging on a Flat Plate. ISIJ International, Vol. 31, No. 4, (n.d. 1991), pp. 342-349, ISSN 0915-1559. 
Hernández, I., Acosta, F., Castillejos, A. \& Minchaca, J. (2008). The Fluid Dynamics of Secondary Cooling Air-Mist Jets. Metallurgical and Materials Transactions B, Vol. 39B, No. 5, (October 2008), pp. 746-763.

Hernández, C., Minchaca, J., Castillejos, A., Acosta, F., Zhou, X. \& Thomas, B. (2011). Measurement of Heat Flux in Dense Air-Mist Cooling: Part II. The Influence of Mist Characteristics on Heat Transfer. Submitted for publication.

Issa, R. \& Yao, S. (2005). Numerical Model for Spray-Wall Impaction and Heat Transfer at Atmospheric Conditions. Journal of Thermophysics and Heat Transfer, Vol. 19, No.4, (October-December 2005), pp.441-447.

Jenkins, M., Story, S. \& David, R. (1991). Defining Air-mist Nozzle Operating Conditions for Optimum Spray Cooling Performance, Proceedings of the Nineteenth Australasian Chemical Engineering Conference, Newcastle, New South Wales, Australia, September 12-20, 1991.

Lefebvre, A. (December 1989). Atomization and Sprays, Taylor \& Francis Group, ISBN 9780891166030. Boca Raton, FL., USA.

Minchaca, J., Castillejos, A., Acosta, F. \& Murphy, S. (2010). Fluid Dynamics of Thin Steel Slab Continuous Casting Secondary Cooling Zone Air Mists, Proceedings of Twentysecond ILASS-Americas Conference on Liquid Atomization and Spray Systems, Cincinnati, OH, USA, May 2010.

Minchaca, J. (2011). Estudio de las Distribuciones de Velocidad y Tamaño de Gota en Rocíos y Nieblas de Agua usados en la Colada Continua del Acero. Ph.D. Thesis in preparation, CINVESTAV-Saltillo, Coahuila, México.

Minchaca, J., Castillejos, A. \& Acosta, F. (2011). Size and Velocity Characteristics of Droplets generated by Thin Steel Slab Continuous Casting Secondary Cooling Air-mist Nozzles. Metallurgical and Materials Transactions B, Vol. 42B, No. 3, (June 2011), pp. 500-515.

Montes, J., Castillejos, A., Acosta, F., Gutiérrez, E. \& Herrera, M. (2008). Effect of the Operating Conditions of Air-mists Nozzles on the Thermal Evolution of Continuously Cast Thin Slabs. Canadian Metallurgical Quarterly, Vol. 47, No. 2, (n.d. 2008), pp. 187-204.

Nasr, G., Yule, A. \& Bendig, L. (Eds.). (September 2002). Industrial Sprays and Atomization: Design, Analysis and Applications, Springer, ISBN 1-85233-611-0, Great Britain, UK.

Puschmann, F. \& Specht, E. (2004). Transient Measurement of Heat Transfer in Metal Quenching with Atomized Sprays. Experimental Thermal and Fluid Science, Vol. 28, No. 6, (June 2004), pp. 607-615.

Sozbir, N., Chang, Y. \& Yao, S. (2003). Heat Transfer of Impacting Water Mist on High Temperature Metal Surfaces. Transactions of the ASME, Serie C: Journal of Heat Transfer, Vol. 125, No. 1, (n.d. 2003), pp. 71-74, ISSN 0022-1481.

Totten, G. \& Bates, C. (Eds.). (January 1993). Handbook of Quenchants and Quenching Technology, ASM International, The Materials Information Society, ISBN 087170448X, Clinton, OH., USA.

Wachters, L. \& Westerling, N. (1966). The Heat Transfer from a Hot Wall to Impinging Water Drops in the Spheroidal State. Chemical Engineering Science, Vol. 21, No. 11, (November 1966), pp.1047-1056. 
Yap, C. (n.d. 1987). Turbulent Heat and Momentum Transfer in Recirculating and Impinging Flows. Ph.D. Thesis, University of Manchester, Manchester, UK. 


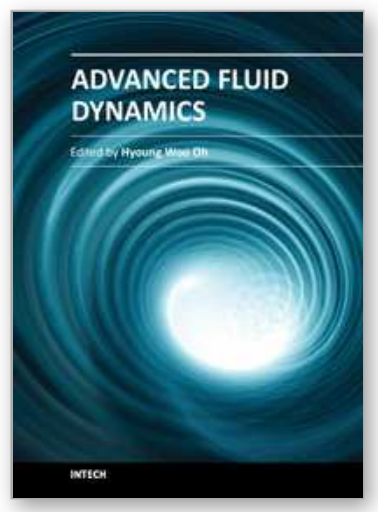

\author{
Advanced Fluid Dynamics \\ Edited by Prof. Hyoung Woo Oh
}

ISBN 978-953-51-0270-0

Hard cover, 272 pages

Publisher InTech

Published online 09, March, 2012

Published in print edition March, 2012

This book provides a broad range of topics on fluid dynamics for advanced scientists and professional researchers. The text helps readers develop their own skills to analyze fluid dynamics phenomena encountered in professional engineering by reviewing diverse informative chapters herein.

\title{
How to reference
}

In order to correctly reference this scholarly work, feel free to copy and paste the following:

Jesús I. Minchaca M., A. Humberto Castillejos E. and F. Andrés Acosta G. (2012). An Experimental and Computational Study of the Fluid Dynamics of Dense Cooling Air-Mists, Advanced Fluid Dynamics, Prof. Hyoung Woo Oh (Ed.), ISBN: 978-953-51-0270-0, InTech, Available from:

http://www.intechopen.com/books/advanced-fluid-dynamics/an-experimental-and-computational-study-of-thefluid-dynamics-of-dense-cooling-air-mists

\section{INTECH}

open science | open minds

\author{
InTech Europe \\ University Campus STeP Ri \\ Slavka Krautzeka 83/A \\ 51000 Rijeka, Croatia \\ Phone: +385 (51) 770447 \\ Fax: +385 (51) 686166 \\ www.intechopen.com
}

\author{
InTech China \\ Unit 405, Office Block, Hotel Equatorial Shanghai \\ No.65, Yan An Road (West), Shanghai, 200040, China \\ 中国上海市延安西路65号上海国际贵都大饭店办公楼 405 单元 \\ Phone: +86-21-62489820 \\ Fax: +86-21-62489821
}


(C) 2012 The Author(s). Licensee IntechOpen. This is an open access article distributed under the terms of the Creative Commons Attribution 3.0 License, which permits unrestricted use, distribution, and reproduction in any medium, provided the original work is properly cited. 